\title{
Comparison of percentage of Daylight Factor values (\%DF) from field work to alternative methods of similar derivations
}

\author{
Sharifah Fairuz Syed Fadzil, Adel Abdullah
}

\begin{abstract}
Field work measurement in the East room from previous work were found to be $2.28 \%$ with a wall to window ratio (WWR) of $50 \%$ and a $\% \mathrm{DF}$ of $1.23 \%$ for a modified WWR of $25 \%$. This paper examines the extent of the field work $\%$ DF values compared to the \%DF values that could be derived for similar cases while using alternative methods. The alternative methods include Building Research Station (BRS) protractors and three other simulation software including ECOTECT, IES $<$ VE $>$ and ReLux. Results found that the \%DF differences between field work values and the alternative methods were minimal. This proves that the \%DF method is still a very reliable method for daylight assessment.
\end{abstract}

Keywords - Daylight factor \%DF, Window to wall ratio (WWR), Building Research Station protractors (BRS), ECOTECT, IES $<$ VE $>$ and ReLux

\section{Introduction}

This paper is is the results of a pilot study conducted at residential rooms at Fajar Harapan which is one of the student dormitories at University Science Malaysia. Using field work data of the Ei/Eo ratios for 6 consecutive days and disregarding the data with effects of direct sunlight penetration, it was found that the $\% \mathrm{DF}$ at mid point of the East facing room was $2.28 \%$ for Window to wall ratio of $50 \%$ and $1.23 \%$ for WWR of $25 \%$. This is explained in detail in the paper by similar authors (submitted as first paper to LRT). That paper explained in detail the history and theory behind \%DF and the nature and characteristics of sky illuminance in Malaysia while using field work data to collect and derive the \%DF values. In this paper, a further development to the study was carried out. This extended study aimed to examine the \% DF values collected through field work that were derived in an east-facing room at Fajar Harapan hostel and compare them to values obtained through various other methods used to obtain this \%DF.

By using relative values which compare indoor to outdoor illuminance, this factor is constant under widely varying outdoor sky and day lighting conditions [1] [2] [3]. Design guidelines worldwide currently recommend daylight provision in terms of the long established DF [5] [6] [7] [8].

Sharifah Fairuz Syed Fadzi

School of Housing, Buildings and Planning (HBP)

Universiti Sains Malaysia (USM)

Malaysia

\section{Adel Abdullah}

School of Housing, Buildings and Planning (HBP)

Universiti Sains Malaysia (USM)

Malaysia

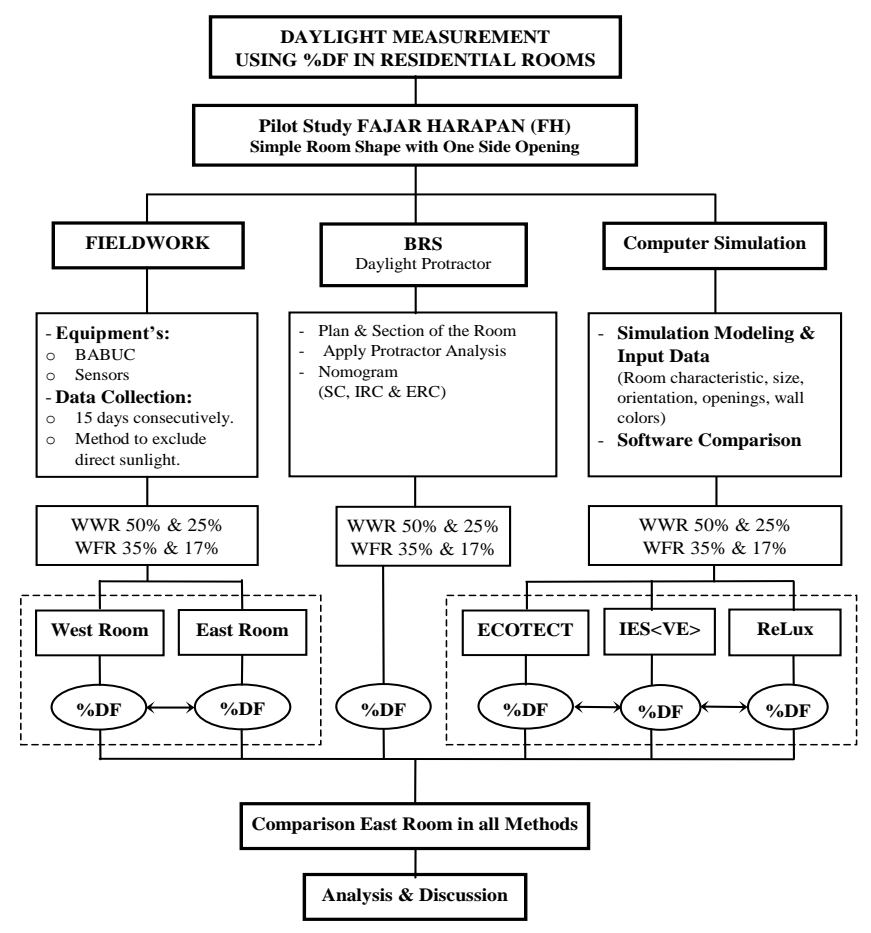

Figure 1. Flowchart of the study

Referring to Figure 1 above, the subject of the study was to assess day light performance in residential rooms. Part 1 of the study has been described in detail in the first paper where a method was devised to calculate \%DF values through data collected through field work which compared east and west facing rooms under real skies in Malaysia. In Part 1, it was found that though similar in design, the east facing room had slightly higher \%DF values compared to west facing rooms. However, field work values alone are not enough to prove their reliability. The field work \%DF values must be compared to similar \%DF values obtained by other methods. The other methods used to establish the \%DF were Building Research Station (BRS) protractors, and three other simulation software including ECOTECT, IES $\langle\mathrm{VE}\rangle$ and ReLux.

\section{Objectives of the Study}

The objective of using of the BRS protractors and the computerized simulation tools in determining the single point \%DF in similar rooms in Fajar Harapan hostel, was to determine how close the field work \%DF data and results were to the protractors and simulations. The study comes with more specific and elaborate objectives as follows: 
- To investigate the effects of different WWR and WFR on the indoor daylight level in a single point via several alternative methods of arriving the $\% \mathrm{DF}$.

- To test and determine the results and performance of several other daylight factor prediction tools namely the BRS protractors and selected daylight simulation programs, and to determine which method is the closest to the results obtained from field work.

\section{Methodology of Pilot Study}

Figure 1 graphically explains the methodology carried out for the pilot study in more detail. The subjects of the research are bedrooms in residential units without regard to whether or not satisfactory daylighting requirements are fulfilled. For the study a simple rectangular room was chosen. Detailed description of the selected rooms was discussed in Part 1 of the first paper, where continuous monitoring and data logging was conducted for 15 consecutive days and the \%DF results were calculated using a specified method. The rooms were measured and calculated with two wall window ratios (WWR) of $50 \%$ and $25 \%$ and WFR of $35 \%$ and $17 \%$.

Indoor natural illumination data were taken in the east room (Le) and west room (Lw) simultaneously to be compared with outdoor illumination (Lo). These data were collected using the Babuc $\mathrm{M}$ data logger that was connected to two indoor luxmeter probes with a maximum reading capacity of 20,000 lux and an outdoor weatherproof luxmeter probe with a maximum reading capacity of 100,000 lux.

TABLE 1. NATURAL ILLUMINATION LEVEL AND DAYLIGHTING FACTOR FOR EAST AND WEST ROOMS (6 DAYS AVERAGE) IN BOTH CONDITIONS WWR $50 \%$ \& WWR $25 \%$

\begin{tabular}{|c|c|c|c|c|c|c|c|}
\hline \multicolumn{8}{|c|}{ East Room } \\
\hline \multicolumn{8}{|c|}{6 Days (10:30am - 3:30pm) } \\
\hline \multirow[t]{2}{*}{ WWR } & \multicolumn{3}{|c|}{$\mathrm{Li}$ (lux) } & \multicolumn{3}{|c|}{ Lo (klux) } & $\overline{\mathrm{DF}}(\%)$ \\
\hline & $\min$ & $\max$ & ave & $\min$ & $\max$ & ave & $\min \max$ ave \\
\hline $50 \%$ & 586.67 & 2104.33 & 952.37 & 28.587 & 523.59 & 421.08 & $1.25 \quad 5.262 .28$ \\
\hline $\begin{array}{c}(10-15 \text { Mar }) \\
25 \%\end{array}$ & 27633 & 06532 & 51530 & 13600 & 41714 & 20112 & 063241123 \\
\hline (16-21 Mar) & $2 / 0.33$ & 905.53 & 515.39 & 13.699 & 417.14 & 291.12 & $\begin{array}{llll}0.63 & 2.41 & 1.23\end{array}$ \\
\hline \multicolumn{7}{|c|}{ Difference } & $\begin{array}{llll}0.62 & 2.85 & 1.05\end{array}$ \\
\hline \multicolumn{8}{|c|}{ West Room } \\
\hline \multicolumn{8}{|c|}{6 Days $(10: 30 \mathrm{am}-3: 30 \mathrm{pm})$} \\
\hline \multirow[t]{2}{*}{ WWR } & \multicolumn{3}{|c|}{$\mathrm{Li}$ (lux) } & \multicolumn{3}{|c|}{ Lo (klux) } & $\overline{\mathrm{DF}(\%)}$ \\
\hline & $\min$ & $\max$ & ave & $\min$ & $\max$ & ave & $\min \max$ ave \\
\hline $50 \%$ & 508.17 & 742.17 & 612.72 & 28.587 & 523.59 & 421.08 & 1.274 .242 .26 \\
\hline $\begin{array}{c}(10-15 \mathrm{Mar}) \\
25 \%\end{array}$ & 10617 & 35382 & 90405 & 12600 & $171^{1}$ & 20112 & 162002 \\
\hline (16-21 Mar) & 100.17 & 353.83 & 224.85 & 13.099 & 417.14 & 291.12 & $\begin{array}{lll}0.28 & 1.62 & 0.82\end{array}$ \\
\hline \multicolumn{7}{|c|}{ Difference } & $0.99 \quad 2.62 \quad 1.44$ \\
\hline
\end{tabular}

A similar method was used to derive the $\% \mathrm{DF}$ and was then carried out for a similar room configuration (selecting only the east facing room) using the BRS protractors and using three other simulation software, namely ECOTECT, IES $\langle$ VE $>$ and ReLux. There are other alternative methods that could have been used to obtain the \%DF but selection was on the basis of what was available to the researcher.

\section{Iv. Deriving the Single Point \%DF Values from BRS Protractor}

The east room at Fajar Harapan hostel was selected to calculate the daylight factor by BRS Daylight protractors using the basic formula $\mathrm{DF}=\mathrm{SC}+\mathrm{ERC}+\mathrm{IRC}$. In this study the calculation considered the Sky Component (SC) and the Internal Reflectance Component (IRC) with empty space (no furniture).

The External Reflectance Component (ERC) was disregarded as being the highest level. There are no external obstructions or buildings nearby in both directions (East or West). In Figure 2 and Figure 3 , the details of the east room plan and section, dimensions and area, as well as the working plane and reference point position are illustrated. All procedures pertaining to the $\% \mathrm{DF}$ calculation using the BRS protractor were followed. The reference point was located in the middle of the room with a height of one meter from the floor level, and 2.22 meters from the center of the window at the same location as the indoor lux meter probe was located when fieldwork readings were taken. The evaluation angle is $23^{\circ}$ in the section, $60^{\circ}$ in a plan, and $17^{\circ}$ form point " $\mathrm{O}$ " which is the reference point to the center of window (Figure 2).

The BRS protractor, is a reliable and established method for deriving the \%DF. Though developed in 1950s this method is still included in most academic books on architecture, environmental science and day lighting [9] However, with the advancements of computer technologies and simulations, the protractors are now not used much by researchers. It is the intention of the researchers to continue with the selection of the BRS protractors to investigate how far the results are from the BRS compared to the field work results, and compared also to other simulation tools.

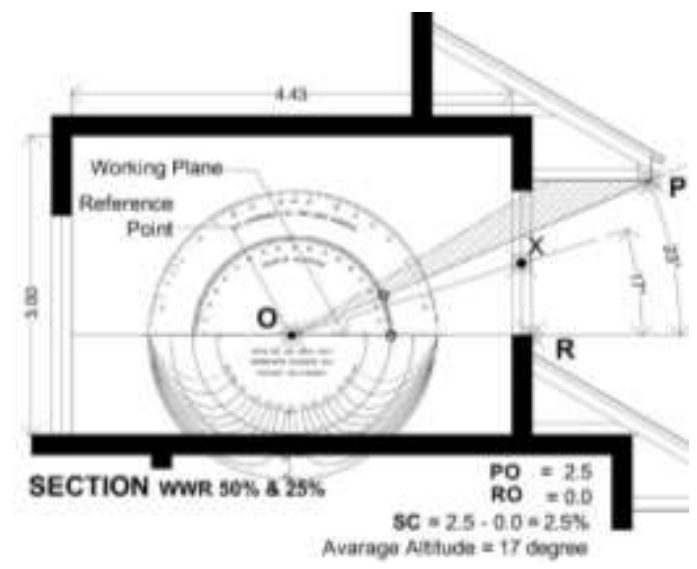

Figure 2. Section of the Fajar Harapan hostel room with the BRS protractor. 
Proc. of The Fifth Intl. Conf. On Advances in Applied Science and Environmental Engineering - ASEE 2016 Copyright (C) Institute of Research Engineers and Doctors, USA .All rights reserved.

ISBN: 978-1-63248-086-6 doi: 10.15224/ 978-1-63248-086-6-10

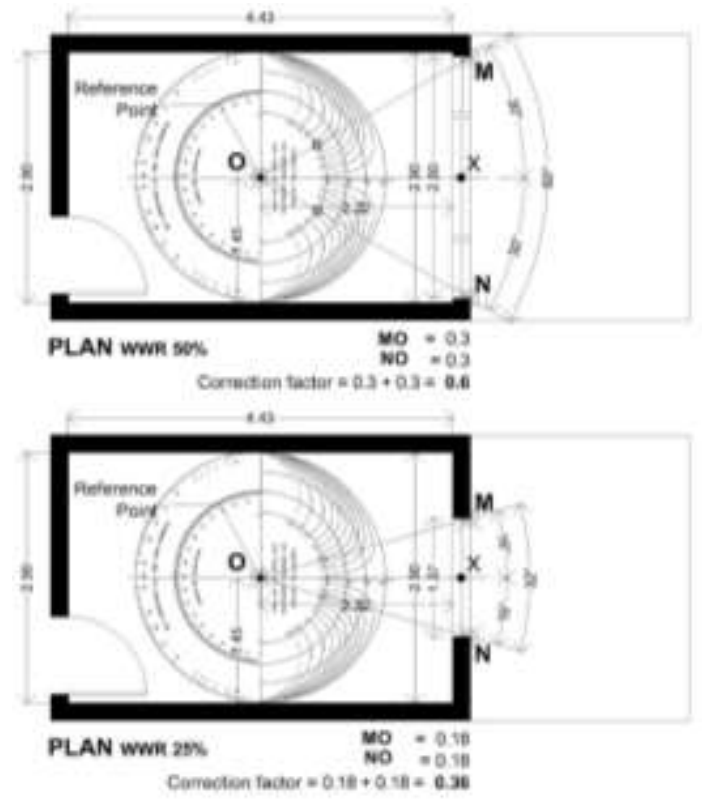

Figure 3. Floor plans of the Fajar Harapan room with the BRS protractor (with WWR 50\% and WWR 25\%).

\section{v. Operation and Results from the BRS}

\section{A. SC Calculation}

The sight lines were drawn from the reference point, mentioned as a point $(\mathrm{O})$, to the edges of the windows on both the sections and the plans (Figure 2 and Figure 3). The center of the primary protractor was then laid over the reference point on the section drawing, and the intercepts of the sight lines from the upper to the lower edges of the window ( $\mathrm{P}$ and $\mathrm{R}$ points) were read off. The values were $\mathrm{PO}$ $=2.5^{\circ}$ and $\mathrm{RO}=0.0^{\circ}$ respectively (see Figure 2 ). Then $2.5-$ $0.0=2.5 \%$ is the value of the sky component for an infinitely long window. The average angle of elevation of the window from the reference point was then read from an ordinary angle protractor. In Figure 2 this is 17 degrees.

The auxiliary Protractor was then laid on the plan drawing with its center on the reference point (O point) and its base on the line parallel to the window. An arc on the auxiliary protractor corresponding to an angle of elevation of $17^{\circ}$ was estimated by eye, and the intercepts with the sight lines to the edges of the window were then read off. The values were $0.3^{\circ}$ on one side and also $0.3^{\circ}$ on the other. In this case a WWR of $50 \%$ was found. Because of that, the reference point was directly opposite the center of the window and the correction factor was $0.3+0.3=0.6$. The value for the infinitely long window was then multiplied by this correction factor giving $2.5 * 0.6=1.5 \%$, which is the corrected Sky Component (SC) for the window of finite length. In the other room, a WWR of $25 \%$ covered case the value 0.18 was read on both sides, so, the correction factor was $0.18+0.18=0.36$. The value of the window with infinite length was $2.5 \times 0.36=0.9 \%$.

\section{B. IRC Calculation}

To calculate the Internally Reflected Component (IRC), the Nomogram method was used (Figure 4), according to [10], the subsequent steps were followed:
1. Find the window area and find the total room surface area (floor, ceiling and walls, including windows) and calculate the ratio of window: total surface area. Locate this value on scale A of the Nomogram.

2. Find the area of all the walls and calculate the wall: total surface area. Locate this value in the first column of the small table (alongside the Nomogram).

3. Locate the wall reflectance value across the top of this table and read the average reflectance at the intersection of column and line.

4. Locate the average reflectance value on scale B and lay a straight-edge from this point across to scale A (to value obtained in step 1).

5. Where this intersects scale $\mathrm{C}$, read the value which gives the average IRC if there is no external obstruction.

The east room measures 4.43 meters by 2.9 meters and 3 meters high, the total surface area (floor, ceiling and walls, including windows) is $69.6 \mathrm{~m} 2$, the wall area is $44 \mathrm{~m} 2$, and the window dimension in the case of the WWR of $50 \%$ is 2.8 meters wide by 1.5 meters high with an area of $4.2 \mathrm{~m} 2$, and $2.1 \mathrm{~m} 2$ (1.4 meters wide by 1.5 meters high) in the case of the WWR of $25 \%$. According to the Nomogram method calculation steps the ratio of wall to total surface area is $0.63 \%$, and the window to total surface area ratio was: $0.057 \%$ for WWR $50 \%$ and $0.028 \%$ for WWR $25 \%$.

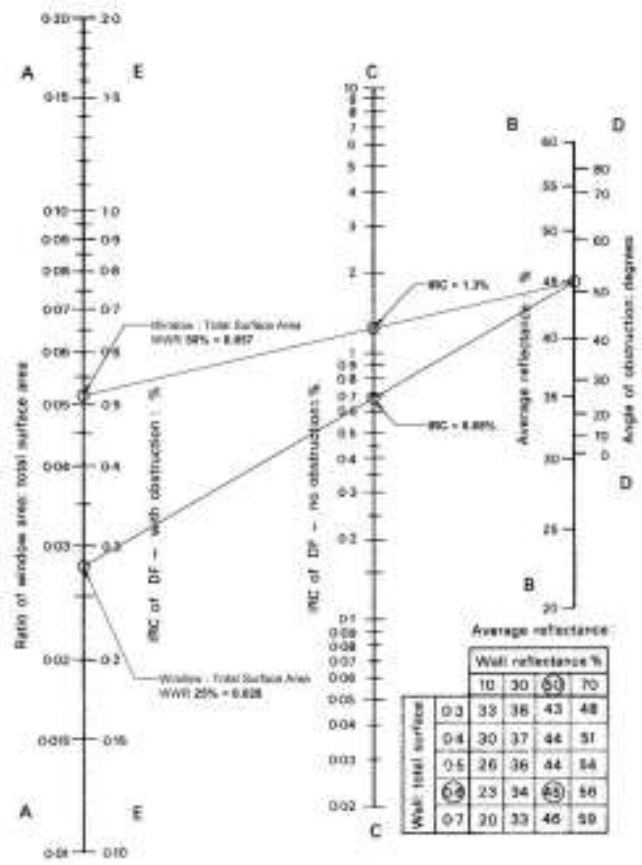

Figure 4. Nomogram for the average of Internally Reflected Component (Koenigsberger et al., 1974).

From the Nomogram graph, the average of IRC is $1.3 \%$ for WWR $50 \%$ and $0.68 \%$ for WWR $25 \%$, when there is no external obstruction. So the total daylight factor according to $\%$ DF formula is as follows: 
Proc. of The Fifth Intl. Conf. On Advances in Applied Science and Environmental Engineering - ASEE 2016 Copyright (C) Institute of Research Engineers and Doctors, USA .All rights reserved.

ISBN: 978-1-63248-086-6 doi: 10.15224/ 978-1-63248-086-6-10

TABLE 2. B.R.S PROTRACTOR DAYLIGHT FACTOR SUMMARY OF RESULTS.

\begin{tabular}{lll}
\hline WWR & \multicolumn{1}{c}{ SC + ERC + IRC } & \%DF \\
\hline $50 \%$ & $1.5+0+1.3$ & $2.8 \%$ \\
$25 \%$ & $0.9+0+0.68$ & $1.58 \%$ \\
\hline
\end{tabular}

\section{vi. Deriving the Single Point \%DF Values from ECOTECT, IES $<$ VE $>$ and ReLux}

Several simulation programs were selected to test the performance of the daylighting of the pilot study. Sketchup tool was chosen to create the test room's simulation model. The main reason for choosing Sketchup for simulation modeling was that it is compatible with many other simulation software and allows compatible import/export modeling with most popular daylight simulation tools.

ECOTECT, IES and ReLux Vision were chosen to simulate the East room under the same conditions and to calculate and simulate the daylighting performance and distribution. The single point \%DF result achieved in the outputs of all of the programs were compared to results from the field work and also to the results derived from the BRS protractors in accordance with the objective of the pilot study.

\section{A. The Experimental Model and Design Conditions}

The room chosen is located inside the main campus of University Science Malaysia (USM) in Penang, Malaysia with a latitude of 5.3 degrees North and a longitude of 100.3 degrees East. It is one of the rooms of the students' hostel buildings called Fajar Harapan. The room is on the 3rd floor of the eastern wing of the building. Daylight analysis was carried out using all the three software under the same design conditions:

- Room design (exactly like the real pilot study room design)

$\circ$ Dimensions and geometry

○ Window area (WWR 50\% and 25\%)

$\circ$ Wall materials and colour

$\circ$ Working plane surface design (area and height from ground floor)

$\circ$ Specific point analysis location and height

o Orientation

- Date (21st March).

- Sky condition and weather file from Penang meteorological data source.
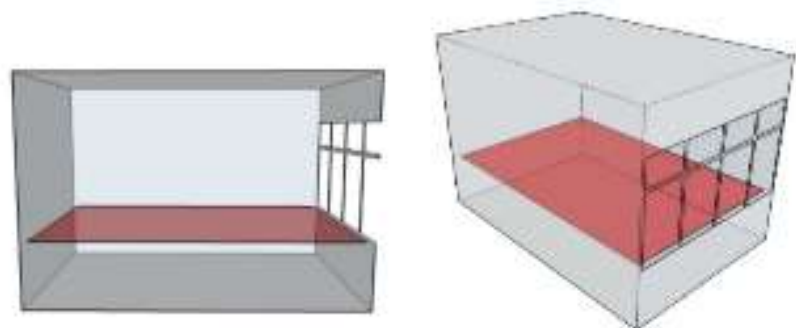

Figure 5. Reference Plane Test Surface Position in 3D models.

The simulations produced graphical results which are shown briefly in Table 9. The mid-point \%DF values from all three simulations are detailed out in Table 3 and Table 4 for ECOTECT; Table 5 and Table 6 for IES $\langle\mathrm{VE}>$ and Table 7 and Table 8 for ReLux. A summary and comparison of all of the methods used to acquire the $\% \mathrm{DF}$ is given in Table 9 and Figure 6.

\section{Results of the Single Point $\% D F$ Values from ECOTECT, IES $<$ VE $>$ and ReLux}

TABLE 3. ECOTECT SUMMARY RESULTS OF A DAYLIGHTING FACTOR FROM WORKING PLANE.

\begin{tabular}{|c|c|c|c|c|c|}
\hline Surface & Quantity & WWR 50\% & WW & $\mathbf{R} 25$ & \\
\hline & & Min. Max. Ave. & Min. & Max. & Ave. \\
\hline $\begin{array}{l}\text { Working } \\
\text { plane }\end{array}$ & $\begin{array}{l}\text { Daylight Facto } \\
\text { (DF) }\end{array}$ & $\begin{array}{lll}1.1 & 14.75 & 3.46\end{array}$ & 0.56 & 13.5 & 1.86 \\
\hline Height of & $\%$ & & & & \\
\hline $\begin{array}{l}\text { evaluation } \\
\text { surface } \\
1.00 \mathrm{~m}\end{array}$ & $\begin{array}{l}\text { Daylight } \\
\text { Illumination } \\
\text { lux }\end{array}$ & $111 \quad 1516352$ & 56 & 1394 & 189 \\
\hline
\end{tabular}

TABLE 4. ECOTECT SUMMARY RESULTS OF A DAYLIGHTING FACTOR A SINGLE POINT LOCATED AT THE MIDDLE OF THE TEST SPACE.

\begin{tabular}{ll}
\hline \multicolumn{2}{l}{ Single Point - 1P (\%DF) } \\
\hline WWR 50\% & $2.17 \%$ \\
WWR 25\% & $1.53 \%$ \\
\hline
\end{tabular}

TABLE 5. IES $<$ VE $>$ SUMMARY RESULTS OF A DAYLIGHTING FACTOR FROM WORKING.

\begin{tabular}{|c|c|c|c|c|c|c|c|}
\hline \multirow[t]{2}{*}{ Surface } & \multirow[t]{2}{*}{ Quantity } & \multicolumn{3}{|c|}{ WWR 50\% } & \multicolumn{3}{|c|}{ WWR 25\% } \\
\hline & & Min. & Max. & Ave. & Min. & Max. & Ave. \\
\hline $\begin{array}{l}\text { Working } \\
\text { plane }\end{array}$ & $\begin{array}{l}\text { Daylight } \\
\text { Factor (DF) }\end{array}$ & 0.62 & 13.93 & 4.13 & 0.35 & 11.55 & 2.87 \\
\hline Height of & $\%$ & & & & & & \\
\hline $\begin{array}{l}\text { evaluation } \\
\text { surface } \\
1.00 \mathrm{~m}\end{array}$ & $\begin{array}{l}\text { Daylight } \\
\text { Illumination } \\
\text { lux }\end{array}$ & 23.2 & 567.5 & 169.3 & 14.3 & 469.7 & 115.4 \\
\hline
\end{tabular}

TABLE 6, SUMMARY RESULTS OF A DAYLIGHTING FACTOR FROM A SINGLE POINT LOCATED AT THE MIDDLE OF THE TEST SPACE.

\begin{tabular}{ll}
\hline \multicolumn{2}{l}{ Single Point - 1P (\%DF) } \\
\hline WWR 50\% & $4.4 \%$ \\
WWR 25\% & $3.2 \%$ \\
\hline
\end{tabular}


Proc. of The Fifth Intl. Conf. On Advances in Applied Science and Environmental Engineering - ASEE 2016 Copyright (C) Institute of Research Engineers and Doctors, USA .All rights reserved.

ISBN: 978-1-63248-086-6 doi: 10.15224/ 978-1-63248-086-6-10

TABLE 7. RELUX VISION SUMMARY RESULTS OF A DAYLIGHTING FACTOR FROM WORKING PLANE.

\begin{tabular}{llllllll}
\hline Surface & Quantity & \multicolumn{3}{c}{ WWR 50\% } & \multicolumn{4}{c}{ WWR 25\% } \\
& & Min. & Max. & Ave. & Min. & Max. & Ave. \\
\hline $\begin{array}{l}\text { Working } \\
\text { plane }\end{array}$ & $\begin{array}{l}\text { Daylight } \\
\text { Factor (DF) }\end{array}$ & 1.3 & 23.5 & 6 & 0.8 & 19.8 & 3.3 \\
$\begin{array}{l}\text { Height of } \\
\text { evaluation } \\
\text { surface }\end{array}$ & $\begin{array}{l}\text { Daylight } \\
\text { Illumination }\end{array}$ & 105 & 1925 & 491.4 & 64.4 & 1642 & 203.7 \\
$1.00 \mathrm{~m}$ & lux & & & & & & \\
\hline
\end{tabular}

TABLE 8. RELUX SUMMARY RESULTS OF A DAYLIGHTING FACTOR FROM A SINGLE POINT LOCATED AT THE MIDDLE OF THE TEST SPACE.

\begin{tabular}{ll}
\hline \multicolumn{2}{l}{ Single Point - 1P (\%DF) } \\
\hline WWR 50\% & $3.7 \%$ \\
WWR 25\% & $2.3 \%$ \\
\hline
\end{tabular}

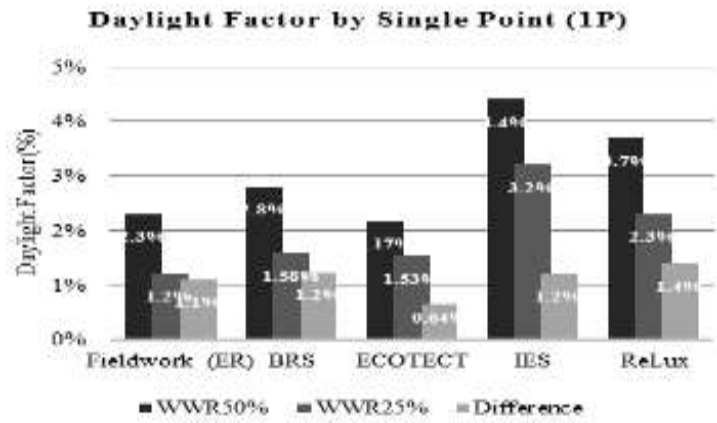

Figure 6. Summary of Daylight Factor for WWR 50\% and WWR 25\% for the Fieldwork, BRS and Simulation Tools.

\section{vIII. Summary and Conclusions}

Several deductions can be made from the study, based on the experimental methods used. From the field work, it was found that in a simple rectangular room design with a single sided opening with a WWR of $50 \%$, or $25 \%$ and a WFR of $35 \%$, or $17 \%$, the average natural illumination received from the Malaysian skies exceeded the standards for typical bedrooms. The rooms with a WWR $25 \%$ and WFR $17 \%$ were found to be illuminated naturally closer to the standards compared to those with a WWR of $50 \%$. This suggests that if natural illumination needs to be closer to the standards, then the WWR cannot exceed certain limits. In the pilot study the effect of the externally reflected component (ERC) is not considered as external obstructions were at too far a distance away to influence the daylight performance of the space.

It can also be deduced that the traditional method of using the BRS protractor founded in 1960s, was found to still be quite accurate to predict the point \%DF second closest to the field work. Though not considered as advanced and sophisticated as the computerized methods, the BRS proved its worth and reliability. As for the computer programs, ECOTECT outperformed IES $\langle\mathrm{VE}\rangle$ and ReLux. This chapter confirms the validity and reliability of the \%DF method to be used for assessing daylighting performance in real spaces under real skies. The other alternative methods to derive the $\% \mathrm{DF}$ were found to produce results quite similar to the field work data.

From the field work and simulation results, the pattern of daylight distribution in both west and east facing rooms can clearly be seen and anticipated with the varied qualities of the Malaysian skies.

\section{Acknowledgements}

Authors would like to acknowledge research funds by the University Science Malaysia and the Malaysian Government under the Fundamental Research Grant Scheme (FRGS) for this research.

TABLE 9. SUMMARY OF THE OUTPUTS ANALYSIS FOR SIMULATION TOOLS COMPARED WITH THE FIELDWORK RESULTS

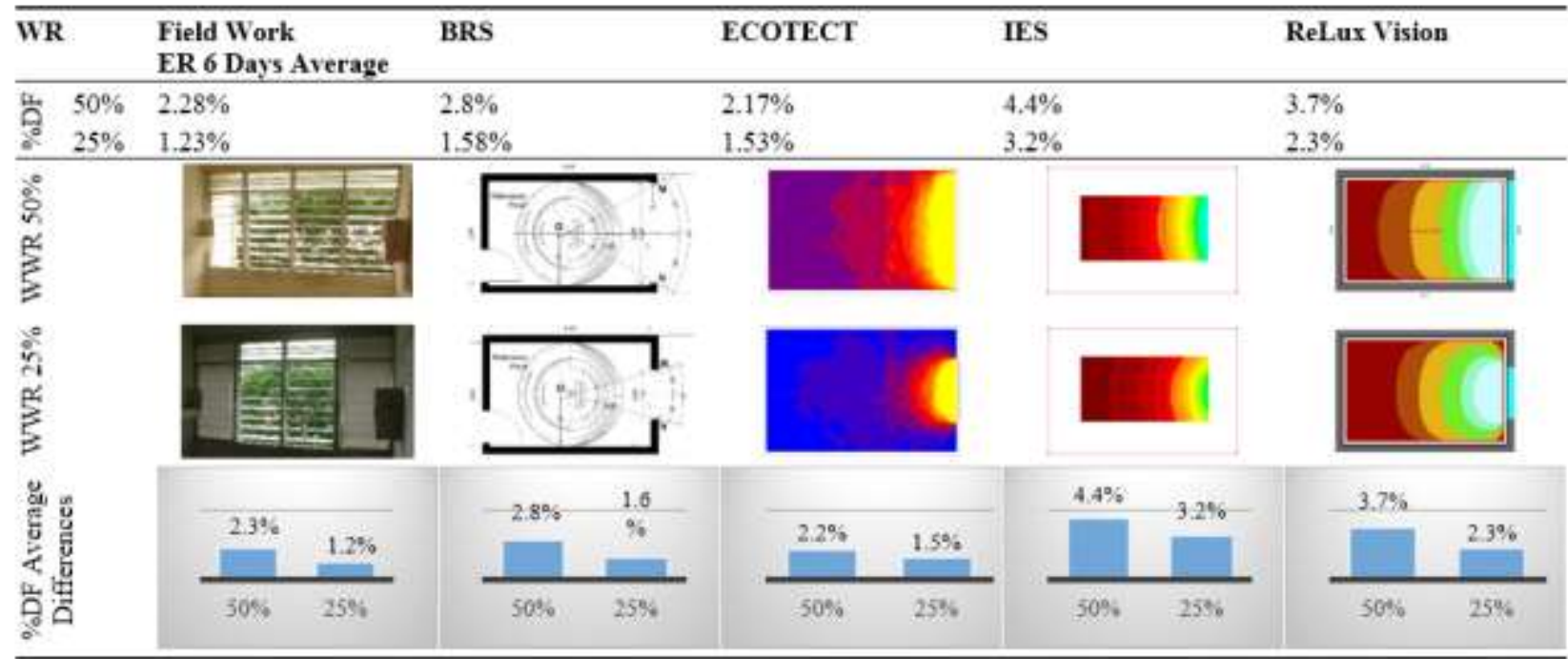


Proc. of The Fifth Intl. Conf. On Advances in Applied Science and Environmental Engineering - ASEE 2016 Copyright $(\odot$ Institute of Research Engineers and Doctors, USA .All rights reserved.

ISBN: 978-1-63248-086-6 doi: 10.15224/ 978-1-63248-086-6-10

\section{References}

[1] M. H. Ahmad, D. R. Ossen, and K. A. M. Khaidzir, Methodology in architectural research, 1st ed. Johor, Malaysia: Universiti Teknologi Malaysia, 2008.

[2] A. Abdullah, S. F. S. Fadzil, and N. A. M. Al-Tamimi, "Daylight Illumination Levels in Varied Room Configurations At the View Condominium, Penang, Malaysia," in 3rd International Conference on Built Environment in Developing Countries (ICBEDC2009), 2-3 December 2009, 2009, pp. 434-447.

[3] S. F. S. Fadzil, W. M. W. Harun, and A. Abdullah, "A Method to Determine a Single Point Percentage Daylight Factor (\%DF) Value from Field Work Data," Adv. Environ. Biol., vol. 9, no. 4, pp. 39-42, 2015.

[4] S. F. S. Fadzi, W. M. W. Harun, and A. Abdullah, "A Method to Determine a Single Point Percentage Daylight Factor (\% DF) Value from Field Work Data," in Postgraduate Conference in Built Environment, 22-24 December 2014, 2014.

[5] J. Mardaljevic, "Climate-Based Daylight Analysis for Residential Buildings," Leicester, 2008.

[6] L. E. Mavromatidis, X. Marsault, and H. Lequay, "Daylight factor estimation at an early design stage to reduce buildings' energy consumption due to artificial lighting: A numerical approach based on Doehlert and Box-Behnken designs," Energy, vol. 65, pp. 488502, 2014.

[7] J. Du and S. Sharples, "Assessing and predicting average daylight factors of adjoining spaces in atrium buildings under overcast sky," Build. Environ., vol. 46, pp. 2142-2152, 2011.

[8] S. F. S. Fadzil, N. A. Al-Tamimi, A. Abdullah, and W. M. W. Harun, "Wall Window Ratio (WWR) and its Influence on Internal Air Temperatures and Natural Light Level in Glazed Room in the Tropics," in ICSAUD 2010 Sustainable Architecture and Urban Design, 3-4 March 2010, 2010.

[9] S. Kota and J. S. Haberl, "Historical Survey of Daylighting Calculations Methods and Their Use in Energy Performance Simulations," in The Ninth International Conference for Enhanced Building Operations, 17-19 November 2009, 2009.

[10] O. H. Koenigsberger, T. G. Ingersoll, A. Mayhew, and S. V. Szokolay, Manual of Tropical Housing and Building, 1st ed. London: Longman Group Limited, 1974.

About Authors:

\begin{tabular}{|c|} 
Assoc Prof Dr Sharifah Fairuz Syed \\
Fadzil is currently the Chair of the \\
Architecture Cluster of HBP, USM. \\
Her specialication include daylighting, \\
thermal performance and building \\
simulations
\end{tabular}

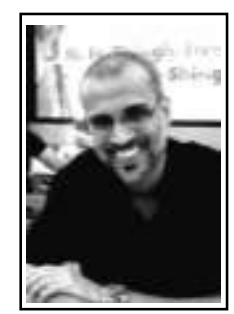

Dr Adel Abdullah

$\mathrm{PhD}$ in daylighting, thermal performance and building simulations

School of Housing, Buildings and Planning, (HBP)

Universiti Sains Malaysia (USM) 